OPEN ACCESS

Edited by:

Thea lonescu,

Babeș-Bolyai University, Romania

Reviewed by:

Teresa Pozo-Rico,

University of Alicante, Spain

Franco Zengaro,

Jacksonville State University,

United States

*Correspondence:

Tegan Reeves PhD ERYT teganjemmareeves@gmail.com

Specialty section:

This article was submitted to Educational Psychology, a section of the journal

Frontiers in Education

Received: 19 March 2021 Accepted: 01 November 2021 Published: 25 November 2021

Citation: Reeves $T$ and White CL (2021) Embodied Instruction: An Exploration and Qualitative Comparison of Expression and Performance of Yoga Instruction

Front. Educ. 6:683139. doi: 10.3389/feduc.2021.683139

\section{Embodied Instruction: An Exploration and Qualitative Comparison of Expression and Performance of Yoga Instruction}

\author{
Tegan Reeves ${ }^{1,2 *}$ and Crystal L. White ${ }^{2}$ \\ ${ }^{1}$ St. Jude Children's Research Hospital, Memphis, TN, United States, ${ }^{2}$ Department of Educational Psychology and Research, \\ University of Memphis, Memphis, TN, United States
}

Background: An inclusive, whole-child model of education is shifting the paradigm into an integrative mind-body approach. Toward contextualizing learning at the close of the cartesian era, the current work explores embodied instruction through the lens of a teacher whose primary focus is the integration of mind and body. Perhaps the longest standing curriculum aimed at embodied learning, yoga provides a unique perspective on techniques and experiences of embodied teaching.

Method: This case study employed an in-depth explorative participatory design to observe instructor intentions in and performance of instruction. Consecutive interviews (5) in conjunction with participatory observation of weekly classes (8) were audio recorded, transcribed verbatim, and triangulated with researcher memos. A grounded and comparative methodology was used to analyze expressed understanding of embodied learning and performed instruction.

Results: In-depth interviews revealed four themes of expressed understanding of embodied instruction: energetic state, personality of instruction, inviting experience and student vulnerability. Participatory observations revealed four themes of performance of embodied instruction: scoping, cadence, silence, and inviting practice. Overlap in expressed understanding and observed instruction were found in each theme. An example of the expressed understanding of a thematic concept is inviting experience: "If someone comes in the very first time and the teacher is very invasive and says, "Do this, do this, do this." And the next pose the teacher is hovering over them, you are not going to go back. You are going to hate it so much [I] let people be really all over the place at the beginning as long as they are safe. [I] allow them that kind of freedom, initially". This was further supported in the observed instruction; an example of this is: "We're going to play with [a posture]. that firmness in your abs, engage the core so a foot might lift. Maybe both feet." And "with the arms firm, maybe the legs straighten".

Conclusion: The current study yields preliminary insight into yoga instruction strategies to support further development of embodied teaching and learning.

Keywords: embodied learning, embodied instruction, embodied teaching strategies, yoga, case study 


\section{INTRODUCTION}

The Cartesian era is rounding a close. Traditional western mentalist thinking in schools no longer serves our goals as educators in an inclusive whole-child model. Through models of embodied cognition, embodied language, and neuroscience evidence for instructional practices that reunite body and mind is growing increasing traction Macedonia (2019). However, specific pedagogical and epistemic components of embodied instruction are not yet part of the educational psychology cannon. Here, we define embodied instruction as an instructional methodology that encompasses the application and use of multimodal communication within a classroom context. Embodied instruction is mainly about teachers or instructors being consciously aware of the moves that they make and the tools they use in the classroom. Similar to metacognition, which deals with thinking about one's own thoughts and processing that information. Embodied instruction deals with an educator's ability to think about (connecting mind and body) their instructional practices and reflecting on how their pedagogy and resources contribute to the design of the students' learning experience.

Regarding the traditional classroom, embodied instruction has been defined as classroom pedagogy that uses the body in space and time (Nguyen and Larson, 2015). However, the construct is new enough to require more inquiry and operationalization. Embodied pedagogy is a novel way to approach traditional classroom learning. Lim (2021) offers a multimodal perspective on embodied pedagogy including gesturing and use of space while Munro (2018) offers learning strategies. In a $2 \times 2$ taxonomy of embodied learning, Skulmowski and Rey, 2018 suggest that task integration and bodily engagement may be used to assess the embodiment of certain instructional choices. Yet, to date, little is explored around teacher beliefs of embodied instruction and how those beliefs interact with performed embodied instruction.

According to Bandura (1978) reciprocal determinism is an educational psychology concept that stems from the social cognitive perspective based on this idea that one's thoughts, feelings, beliefs, and environment all influence each other in determining a person's actions in a certain situation or circumstance. In other words, how we act is influenced by the environment, individual characteristics, and behavior. In fact, all three factors are influenced by each other in a reciprocal and intertwined manner. Similarly, embodied instruction and learning views learning and teaching as an entangled and joined union between the body and the mind in a physical and mental act of knowledge construction. This mind-body/ physical-mental union entails thoughtful awareness of one's own body, space, and social context.

Thus, a potential curriculum that may inform embodied pedagogy is one that focuses exclusively on embodied learning and embodied instruction. Yoga holds such a goal in its very etiology. Deriving from sanskrit, yoga is commonly cited as meaning to "yoke" or unite. Additionally, yoga is uniquely positioned to inform such inquiry as it is a form of experiential learning led by a qualified teacher (Musial, 2011).
The long-standing tradition of embodied instruction is demonstrated by the lineage-base of yoga curriculum Broad (2012). Scholars often discuss that yoga treats mind, body, and spirit as an integrated unit Tyberg (1940). The four main components of yoga in schools are voluntary breathing, purposeful movement, mindful meditation and relaxation (Butzer et al., 2015; Matko et al., 2021).

While it is outside the scope of the current work, it should be noted that there is a great deal of evidence for the efficacy of yoga in schools toward overall wellness (Frank et al., 2014; Waechter et al., 2021). Skill acquisition includes embodied mindfulness Salmon et al. (2009), physical fitness (Butzer et al., 2016), existential introspection (Khalsa, 2015), and resilience Reeves and Holden (2016). Mechanisms of learning or instruction are less often explored but Gangadhar, 2015 postulated that physical imitation of postures may increase feelings of connectedness in clinical populations (2015). While pivotal work continues to be done to understand yoga instruction and mechanisms of change, the current study seeks to understand embodied teaching (i.e. expressed perception and performed instruction) that may transcend specific curriculum.

By shifting the focus from yoga itself to learning, both the educational psychology and yoga research fields may gain meaningful traction toward conceptualizing embodied teaching and contextualizing embodied learning.

This case study was designed to identify potential parameters that may inform subsequent research. Indeed, little to no research has been done in the area of yoga instruction to inform classroom instruction. As such, it is not consistent with the aim or methodologies to test hypotheses. Rather, this qualitative study is an open inquiry to identify naturally emerging themes of expressed understanding (e.g. epistemology) and performance (e.g. pedagogy) of embodied learning through the lens of a public recreational yoga class instructor.

\section{METHODOLOGY}

Employing an in-depth exploratory design involving consecutive interviews (5) sequentially aligned with participatory observation of weekly classes (8). The instructor and students participating in the observation were informed and consented to be part of the research. This study was approved by the authors Institutional Review Board.

\section{Participant and Setting}

Using purposive sampling (Patton, 1990) a popular local yoga instructor who also had experience in a traditional classroom was selected. The yoga instructor participant had over 15-years of yoga teaching experience with a $200 \mathrm{~h}$ RYT (Registered Yoga Teacher certification and trainings in numerous lineage-based styles of yoga (i.e. Iyengar and Yin). In addition, the yoga instructor participant was actively teaching English classes at a local community college at the time, and therefore able to reflect on the transcendent nature of embodied instruction topics discussed. Classes observed were weekly classes open to all local students. The classes were 50-min long and consisted of 
the four previously mentioned components of yoga in schools: voluntary breathing, physical postures (and purposeful movement), meditation and relaxation. Most classes had between eight and twenty students from a diverse campus population. The classes were secular in nature and offered a blend of traditional postures, breathing and mindful movements with a themed playlist of modern music.

\section{Data Collection}

To gather information about expressed understanding of embodied instruction, four in-depth semi-structured interviews with the participant and researcher as conversational partners (Rubin and Rubin, 2007) were strategically and sequentially scheduled between yoga class observations. Each interview lasted between 60- and 90-min. Interviews were audiorecorded and transcribed verbatim. To explore performed embodied instruction, eight participatory observations (Emerson et al., 1995) were scheduled. Each class was 50-min long. Classes were audio recorded and transcribed verbatim.

Other sources of data collected include memos, notes, and student surveys. Finally, a fifth in-depth interview structured around the overall findings was used as a participant check for accuracy (Creswell and Miller, 2000; Creswell and Clark, 2004; Hamilton, 2020). This interview was not transcribed or coded. However, research memos were used to gain insight into the posthoc expression of any further pedagogical concepts.

\section{Analysis}

Using grounded theory (Charmaz, 2003) and a theoretical lens derived preliminary beliefs investigation (Reeves and Azim, 2016), an iterative coding process using constant comparative methods was used to identify themes of embodied instruction. This happened in five overlapping phases. First, interviews were coded for expressed beliefs and intentions using an open line-byline coding. Then, observations were organized into segments and synthesized with researcher memos, with subsequent memoing of possible overlap. Third, interviews were recorded using emergent line-by-line concepts and a reciprocal deterministic framework (Bandura, 1978). Phases one through three informed a flexibly designed codebook of persistent concepts (i.e. themes). To triangulate the transcriptions, observations, and student surveys the flexible codebook was used within, ATLAS. ti seven software to code for presence of concepts and to identify the areas of intersection amongst themes. Finally, class observations were systematically analyzed for theme presence using a fuzzy-set dichotomous data matrix (Schneider and Wagemann, 2015) in order to identify whether expressed understanding could be interpreted by performance.

\section{FINDINGS}

Findings presented offer initial themes that may further meaningful interpretation of expressed and performed understanding of embodied instruction. Through persistent concepts (i.e. themes), intersections of concepts, and observed presence of themes performed during instruction, the current findings offer insight into the conceptualization and contextualization of embodied learning.

\section{Persistent Findings}

The iterative process of the project allowed persistent findings to be identified across expression and performance. Persistent themes were developed through defining and redefining concepts discussed: Embodied Learning/Experiential Change, Instructional Technique/Instruction Choice, Personality of Instruction, Connecting, Energetic State, Pacing/Cadence, Inviting Experience, and Scoping. Table 1 presents examples of these findings.

Embodied learning and experiential change dealt with the participants learning through experience how their mind and body were processing and adjusting to the yoga movements. During this process, it was imperative that the participants make quick adjustments to their poses that not only aligned with the yoga poses, but also what felt right based on how and what they were learning from the instructor. Instructor beliefs around this theme were the experiential and transformational aspects of feeling the body in the yoga.

Instructional Techniques/Instruction Choice centered around the instructor's pedagogical ability and experience to know how and when to make the best instructional choices and changes in the moment while still requesting the students to master the various yoga techniques. This is evident in the instructor's word choice and quick adjustments to the technique/poses in the moment.

Personality of Instruction encompasses the importance of teacher or instructor personal characteristics on the classroom context and how it impacts or alters one's classroom learning experience. Instructor beliefs displayed a commitment to and belief in diversity in personality and class persona.

Connecting involved discussion around relational and social learning demonstrated by student teacher connection-points as well as student-to-student connections. Instructor beliefs around this illustrated the importance of attentive and relational instructor choices as it relates to student experience.

Energetic State was a persistent discussion point around intangible assessment via scoping the classroom or a felt sense. The term was derived from en vivo code of transcription describing the choices made based on the class' "group energetic state" in the beginning of class. The theme appeared in other parts of the interview and researcher memos. For example, when asked about the ability to evenly time postures as observed, the interviewee had difficulty explaining any method of timing he simply "felt agitation in his body" and moved from the posture. This supports the research design and future directions using a multi-layered data collection technique.

Pacing/Cadence was discussed as instruction choice based on an internal assessment of student needs. It was measured through timestamps and observation memos as well as stated beliefs by the instructor.

Inviting Experience was a belief and observation of instruction technique commonly stated as an important way to increase student engagement. Evidence of performance was gleaned from class observation memo and transcription. Instructor beliefs 
TABLE 1 | Persistent findings.

\section{Theme}

\section{Embodied Learning/}

Experiential Change

Technique/Instructional Choice

Personality of Instruction

Connecting

Energetic State

Pacing/Cadence

Inviting Experience
Expressed understanding

Like anything else, just because something feels normal doesn't necessarily mean it is normal. It's very true in yoga. If everybody is doing the posture just right it's not shifting them into new places.

It's the experience. They're coming back again and agian and they're like "Wait a minute, my foot, that feels weird. What if I do this?" Then they do that and they're like "Okay, yeah, that feels good".

The energy really starts to shift. After [warrior] I go to a twist. I do a twist and then I start longer holds, seated holds. That is when the energy starts to quickly settle down.

like for instance "[knee at 90 degrees] track your knee with the second and third toe" [instead] "I'd try to make a point of saying to protect your knee and stretch your inner thigh and to make it in terms of this is the benefit" not to do this because it is the right wat. [Instead] "Hey try this. See what happens".

Some of those teachers are very, very popular and they have very loyal students. You would think, an authoritarian teacher will drive people away, that is not necessarily true.

The thing about subbing is that I cannot teach somebody else's class. I can modify it [but] I am not going to pretend that I am another teacher.

if there is [a student] who needs it I will zero in on somebody and make [a general] comment to the class, but I will look at them and they are looking at me. No one else in the class knows, its not like going up and calling them by name

It really has to do with where I feel the energy is and where I like for it to be. If I feel like it should be a little bit different place, then I'll speed it up. I very rarely slow it down because it naturally occurs.

There are times when [students] are really distracted. Sometimes people are very their energy is very subdued on the other extreme.

A lot of times what I will do is a very physically challenging sequence at the beginning to kind of use up that energy, to focus it. Sometimes we will move a little bit faster that usual and when you are moving fast, you have to pay attention. It's not like you get up in the morning and you stay there for $30 \mathrm{~s}$ because in that $30 \mathrm{~s}$ they have a lot of time to get out of their awareness. By moving and keeping them moving it keeps them focused.

I feel like it's my job to bring some balance but I don't feel like it is my job to go in and say, "Okay, you were supposed to feel this way." Instead, to let people be where they are emotionally at the moment. At the same time say, "Let's try to lighten it up and see what happens." Let's move a little bit faster and see if that doesn't bring you out of your head, but it's okay if people aren't.

Unless they are doing something that is dangerous [I] just let them go and do. Then, if they come back and they start to come back regularly, then [I] focus more on "Why don't you try this?" "Why don't you try that?".

I let people be where the are.

Scoping
II] can tell by the body. Are they slumping? Are they alert?

Scoping can tell by the body. Are they slumping? Are they alert?
I watch the students all the time. I watch the regulars and they get it.

\section{Performed instruction}

*

Class structure had consistency with small changes. Namely, consistent instruction through sun-salutations within the first 20 min; varied instruction through a peak posture; extremely consistent progressive relaxation for savasana.

I'll get the playlist started. As always the playlist has a theme. Bonus karma points if you guess the theme. \{mumbles\} see if I can get the thing going.

If you want to go a little deeper take your right hand push forward, raise your left.

Example from researcher memo: "There was a lot of noise and commotion at the beginning of class. After class (specifically after Savasana) the change in "energy" seemed tangible. Wish there was a way to measure that".

Class 2, 4, 6, 7, 8 consistent timing, lengthening in seconds throughout class.

All posture holds that included right and left side were consistent within $15 \mathrm{~s}$ of each other. Example from researcher memo.

"Class 5: Pigeon on side one was 1 minute 21 s on side two was 1 min $23 \mathrm{~s}$ - researcher note "how does he do that?"”.

We're going to play with [a posture]. ... that firmness in your abs, engage the core so a foot might lift. Maybe both feet.

Find your way to ...

Send your left hip underneath the right.

We're going to come to [a posture]. Imagine someone is pulling your wrists in opposite directions.

Bring your awareness to whatever feelings may be arising.

Arms straight. Relax. Maybe straighten your legs.

Words are verbatim from interview, with the exception of bracket use to denote meaning inferred earlier in text. Italicized text is researcher notes and not direct quotations. Themes are listed by most common to least common. Examples are arbitrarily chosen by author.

*See note to the right. 
TABLE 2 | Presence of expressed themes per class.

\begin{tabular}{lcccccccc}
\hline & $\mathbf{1}$ & $\mathbf{2}$ & $\mathbf{3}$ & $\mathbf{4}$ & $\mathbf{5}$ & $\mathbf{6}$ & $\mathbf{7}$ & $\mathbf{8}$ \\
\hline Embodied Change & $*$ & $*$ & $*$ & $*$ & $*$ & $*$ & $*$ & $*$ \\
Teaching Choice & 0 & 1 & 1 & $*$ & 0 & $*$ & 1 & 1 \\
Personality & 0 & 1 & 1 & 1 & 0 & 1 & 1 & 1 \\
Connecting & 1 & 1 & 0 & 0 & 1 & 1 & 0 & 0 \\
Energy & $*$ & $*$ & 1 & $*$ & $*$ & $*$ & $*$ & $*$ \\
Pacing & 1 & 1 & 1 & 1 & 1 & 1 & 1 & 1 \\
Inviting & 1 & 1 & 0 & 1 & 1 & 1 & 0 & 1 \\
Scoping & 0 & 1 & $*$ & 0 & 0 & 0 & 1 & 0 \\
\hline
\end{tabular}

around inviting described a desire to allow students to choose what class choices they wanted to make.

Scoping was a stated instructional choice around assessing students' reception of instruction and watching for safety. It was noted in observational memos as well as stated as a belief around describing how to cue or modify language.

\section{Intersections}

Coding and frequency analysis allowed for intersections between themes to be analyzed. Intersections demonstrate ways information about overlap in thematic expression which may inform the lead of ideas and concepts. The following intersections were observed: Inviting Experience always intersected with another theme; Connecting (e.g. student vulnerability) often intersected with embodied change; Connecting with Students intersected with every theme except pacing; Teaching Technique/ Instructional Choice and Embodied Learning/Experiential Change intersected most often with other themes; Pacing/ Cadence intersected the least with other themes.

\section{Presence of Expressed Themes Performed}

Presence of construct are coded using fuzzy-set dichotomous codes (Schneider and Wagemann, 2015). Threshold and identification was designed by theme (i.e. at least once; $25 \%$; etc.) and informed by interview data $(0=$ construct not present or identified, 1 = construct present or identified). Inter-rater reliability was used to discern the presence of a particular theme in the observation-when agreement was not made on the presence the code was labeled as a ${ }^{\star}$ instead of one or 0 . There was discrepancy in the most common theme, Embodied Change and Energy. Attribution of discrepancy was around subtle belief or experience differences in researchers. Pacing was present in every observation by way of timestamps. Inviting Experience and personality of instructor were observed during a majority of the observations ( 6 of the eight classes). Scoping was not observed in a majority of the observations ( 2 of the eight classes). Table 2 presents the fuzzy-set data analysis.

\section{Post-hoc Expression}

The final interview was designed to be a form of participant checking after analysis. This interview data allowed for discussion around themes and probing around the themes observed in classes. While most of the discussion confirmed findings, depth of understanding was also gained. For example, when asked about the ability to evenly time postures as observed, the interviewee had difficulty explaining any method of timing he simply "felt agitation in his body" and moved from the posture. This supports the research design and future directions using a multi-layered data collection technique.

\section{DISCUSSION}

The current findings offer insight into the beliefs and performance around embodied instruction from a mind-bodycentric instructor (i.e. yoga). Specifically, the findings fall into two categories: 1) Beliefs about embodied learning and instruction; and 3) Specific strategies of embodied instruction.

\section{Beliefs About Embodied Learning and Instruction}

The strongest belief around embodied learning was presented in the ways that the participant discussed experiential learning through awareness of the body. This concept may prove to be useful in understanding teacher buy-in of embodied learning. As teacher beliefs are connected to student outcomes (Usher and Pajares, 2008) it is important to consider the belief in the student's ability to learn through their own embodied experiences.

These beliefs may also influence self-efficacy or confident performance of the instructor. For example, the observed accuracy in which pacing happened between sides (e.g. right and left) seemed unconsciously performed. This belief in embodied learning and trust in oneself as a teacher to impart it seemed an important, though difficult to consciously reproduce, component to the ease in which embodied instruction was provided. Another possible explanation may be a mastery status of embodied learning (Seligman, 2003). Once a level of mastery has been reached an automaticity in action relinquishes the need for acute attention. Mastery, or performance at an automatized level, may explain difficulty expressed in explaining the precision in which specific postures were paced. Researchers across fields do not agree on ways to measure, assess, or evaluate mastery. In the future, however, including theoretical or empirical exploration on this embodied mastery in embodied instruction may offer rich insight into embodied learning itself.

An interesting finding around the role of embodied instructors was personality and style. The participant expressed the importance of diversity and choice in personality. The expressed theme of personality, in style and teacher, is one such finding. Groessl et al. (2015) suggests that mechanisms of change are observable and have connection to style or personality of instruction, however the work centers around observed expression and not through the teachers' identified beliefs or expressions of understanding. Future work that incorporates both self-reported (i.e. expressed) understanding and observed (i.e. performed) understanding would more properly illuminate individual differences of instructors. This finding is supported by work in an existing research field: educational psychology.

\section{Specific Strategies of Embodied Instruction} Specific teachable strategies in the current findings include: 1) Inviting; 2) Scoping; and 3) Connecting. 
The finding of Inviting Practice in the interviews was underscored by discussion around the instructor "inviting" instead of "telling". For example: "Unless they are doing something that is dangerous [I] just let them go and do. Then, if they come back and they start to come back regularly, then [I] focus more on "Why don't you try this?" "Why don't you try that?" Inviting experience into a contemplative discipline has been studied in similar research. In the Handbook of Mindfulness in Education Roeser explores inviting through a literary analysis of mindfulness instruction over time. One of the qualitatively observable performances of teachers in mindfulness practice is inviting experience (Roeser, 2016). Of the themes that dominated the interviews and observations, Inviting Experience was an expressed theme with significant frequency in observations. Roeser (2016) literary analysis through observations and verbatim transcriptions similar to the current study's observations; however, software use and specific analysis techniques differ. Future research could use this analysis with expressed understanding (i.e. interviews) and student expressed experience to better understand the impact of the presence, or lack, of inviting experience might help contextualize the context more.

Scoping was a theme specifically discussed as class energy and individual student assessment. The concept of class energy is novel to the traditional classroom but it may conflict with long-held beliefs around behavior management. The current findings suggest possible strategies offering a balance or compliment to class energy. For example, if it is perceived through scoping that the energy of the class is high and excited the instructor would offer activity that could compliment the energy and offer an opportunity for engagement. If applied instead of authoritative structures (i.e. sit and be quiet) in the traditional classroom this may lessen disappointment of unmet expectations around obedient/subservient behavior and decrease student to teacher friction. Also, potentially important in this discourse is the current finding of Connecting.

Research on mindfulness practice in psychology also informs the intersection observed of student vulnerability and connectedness. The overlap (50\%) in expressed understanding of student vulnerability and expressed importance in connection to students suggests that a feeling of connectedness to students is an important component of the yoga practice, specifically in holding a safe emotional space. In a theoretical and qualitative exploration of yoga instruction, McClure (2015) talks about the holding environment or the container. Connectedness may be a component of this container. Kabat-Zinn (1994), believes that connectedness plays a part in the process of learning through mindfulness. His popular training (i.e. MBSR: Mindfulness Based Stress Reduction) incorporates components of yoga and culminates in compassion practice that attempts to build from, and increase, feelings of connectedness. Theoretical research may also drive an understanding of intersections and overlap. Specifically, the overlap (50\%) in student vulnerability and connectedness may align with constructs of social cognitive learning. Vygotsky (1978) suggests that learning is social in nature and that feeling of connectedness may be reciprocal and predict performance.

\section{Limitations}

The current study aimed to explore the beliefs and performance of embodied instruction by a single instructor of embodied learning and therefore is not generalizable across mind-body, yoga, or instructional practices. Future research should explore the themes that emerged to better understand the transferability to the traditional classroom.

Furthermore, while performance of some of these belief constructs were observed, not all themes could be seen by researchers. Similarly, some themes observed, such as mastery of instruction through pacing or cadence were difficult to express through interviews. For example, Embodied Learning/Experiential Change and student Energetic State is an important component of interviews, however, can only be subjectively observed without student feedback or probing. More in-depth examination and perhaps measurement of the shared understanding or experience of embodied learning should be done.

\section{CONCLUSION}

The current study offers preliminary concepts of embodied instruction beliefs and strategies that may be used by an embodied instructor. Through in-depth interviews and class observations, themes emerged that demonstrated beliefs such as experiential embodied change, group/collective energy, connection with students, personality of instructor that are supported by concepts of mastery, self-efficacy, and individual differences. Furthermore, these interviews and class observations revealed strategies such as scoping, cadence, and inviting experience that are supported by current work in mindfulness training, social cognitive learning, and reciprocal determinism.

\section{DATA AVAILABILITY STATEMENT}

The datasets presented in this article are not readily available because it is not possible to anonymize data and maintain the privacy of the participants. Requests to access the datasets should be directed to teganjemmareeves@gmail.com.

\section{ETHICS STATEMENT}

The studies involving human participants were reviewed and approved by The University of Memphis Institutional Review Board. The patients/participants provided their written informed consent to participate in this study.

\section{AUTHOR CONTRIBUTIONS}

TR was responsible for the design, data collection, analysis, interpretation, and presentation of the data. CW aided in interpretation and presentation of the data.

\section{ACKNOWLEDGMENTS}

The author would like to thank the following individuals for their contribution to the analysis and continued review of the qualitative process: Tiffany Rybak, Joseph Dunn, and Rita Jorgenson. 


\section{REFERENCES}

Bandura, A. (1978). The Self System in Reciprocal Determinism. Am. Psychol. 33 (4), 344-358. doi:10.1037/0003-066x.33.4.344

Barnes, P. M., and Bloom, B. (2008). Complimentary and Alternative Medicine Use Among Children in the Unites States. Annu. Health Sci. Rep. 12, 20091250.

Broad, W. (2012). The Science of Yoga: The Risks and the Rewards 1st Edn. New York: Simon \& Sculster.

Bordo, S. (1986). The Cartesian Masculinization of Thought. Signs: J. Women Cult. Soc. 11 (3), 439-456. doi:10.1086/494250

Butzer, B., Bury, D., Telles, S., and Khalsa, S. B. S. (2016). Implementing Yoga within the School Curriculum: a Scientific Rationale for Improving SocialEmotional Learning and Positive Student Outcomes. J. Children's Serv. 11 (1), 3-24. doi:10.1108/JCS-10-2014-0044

Butzer, B., Ebert, M., Telles, S., and Khalsa, S. B. S. (2015). School-Based Yoga Programs In The United States: A Survey. Adv. Mind Body Med. 29 (4), 18-26.

Charmaz, K. (2003). "Grounded Theory: Objectivist and Constructivist Methods," in Strategies of Qualitative Research. Editors N. K. Denzin and Y. S. Lincoln (Thousand Oaks, CA: Sage Publications), 249-291.

Clough, P. T. (2008). (De)Coding the Subject-In-Affect. Subjectivity 23, 140-155. doi:10.1057/sub.2008.16

Creswell, J. W., and Clark, V. L. P. (2004). Principles of Qualitative Research: Designing a Qualitative Study. Lincoln: Office of Qualitative \& Mixed Methods Research, University of Nebraska.

Creswell, J. W., and Miller, D. L. (2000). Determining Validity in Qualitative Inquiry. Theor. into Pract. 39 (3), 124-130. doi:10.1207/s15430421tip3903_2

Crotty, M. (1998). "Introduction: The Research Process," in The Foundations of Social Research: Meaning and Perspective in the Research Process (London: Sage Publication), 1-17.

Denzin, N., and Lincoln, Y. (20052005b). "Introduction: The Discipline and Practice of Qualitative," in The Sage Handbook of Qualitative Research. Editors N. Denzin and Y. Lincoln. 3rd edition (Thousand Oaks: Sage Publications), 1-32.

Emerson, R. M., Fretz, R. I., and Shaw, L. L. (1995). "In the Field: Participating, Observing, and Jotting Notes," in Writing Ethnographic Fieldnotes (Chicago, IL: The University of Chicago Press), 17-38.

Frank, J. L., Bose, B., and Schrobenhauser-Clonan, A. (2014). Effectiveness of a School-Based Yoga Program on Adolescent Mental Health, Stress Coping Strategies, and Attitudes toward Violence: Findings from a High-Risk Sample. J. Appl. Sch. Psychol. 30 (1), 29-49. doi:10.1080/15377903.2013.863259

Gangadhar, B. N. (2015). "Yoga for Psychosis: New Promise from an Ancient Science," in Presented at the Annual Yoga Research Symposium (Stockbridge, MA, USA. September.

Groessl, E. J., Maiya, M., Elwy, A. R., Riley, K. E., Sarkin, A. J., Eisen, S. V., Braun, T., Gutierrez, I., Kidane, L., and Park, C. L. (2015). The Essential Properties of Yoga Questionnaire: Development and Methods. Int. J. Yoga Therap 25 (1), 51-59. doi:10.17761/1531-2054-25.1.51

Hagins, M., Haden, S. C., and Daly, L. A. (2013). A Randomized Controlled Trial on the Effects of Yoga on Stress Reactivity in 6th Grade Students. EvidenceBased Complement. Altern. Med. 2013, 1-9. doi:10.1155/2013/607134

Hamilton, J. B. (2020). Rigor in Qualitative Methods: An Evaluation of Strategies Among Underrepresented Rural Communities. Qual. Health Res. 30 (2), 196-204. doi:10.1177/1049732319860267

Kabat-Zinn, J. (2009). Mindfulness-based Interventions in Context: Past, Present, and Future. Clin. Psychol. Sci. Pract. 10, 144-156. doi:10.1093/clipsy/ bpg01610.1093/clipsy.bpg016

Kabat-Zinn, J. (1994). Wherever You Go There You Are: Mindfulness Meditation in Everyday Life. New York, NY: Hyperion.

Khalsa, S., Butzer, B., Shorter, S., Reinhardt, K., and Cope, S. (2013). Yoga Reduces Performance Anxiety in Adolescent Musicians. Altern. Therapies 19 (2).

Khalsa, S. (2015). Yoga in Schools. Presented at the Annual Yoga in Schools Symposium. Stockbridge, MA, USA. September.

Lim, F. V. (2021). Designing Learning with Embodied Teaching: Perspectives and Multimodality. New York, NY: Routledge.

Macedonia, M. (2019). Embodied Learning: Why at School the Mind Needs the Body. Front. Psychol. 10, 2098. doi:10.3389/fpsyg.2019.02098

Matko, K., Bringmann, H. C., and Sedlmeier, P. (2021). The Effects of Different Components of Yoga: A Review of Comparative Studies and Meta-Analyses.
McClure, B. (2015). Yoga Therapy: Building a Holding Environment for Somatic and Psyche Change. Int. J. Yoga Therap 25, 21-26. doi:10.17761/1531-2054-25.1.21

Munro, M. (2018). Principles for Embodied Learning Approaches. South Afr. Theatre J. 31 (2), 1-10. doi:10.1080/10137548.2017.1404435

Musial, J. (2011). Engaged Pedagogy in the Feminist Classroom and Yoga Studio. Feminist Teach. 21 (3), 212-228. doi:10.5406/femteacher.21.3.0212

Nguyen, D. J., and Larson, J. B. (2015). Don't Forget about the Body: Exploring the Curricular Possibilities of Embodied Pedagogy. Innov. High Educ. 40 (4), 331-344. doi:10.1007/s10755-015-9319-6

Patton, M. (1990). Qualitative Evaluation and Research Methods. Beverly Hills, CA: Sage, 169-186.

Reeves, T. J., and Azim, K. B. (2016). ) Learning from Convergence: Instruction Strategies from a Mind-Body Practice. USA: Presentation at The Twelfth International Congress of Qualitative Inquiry in Champaign-UrbanaIL. May.

Reeves, T. J., and Holden, S. (2016). 10 Minutes Better: Yoga And Mindfulness Professional Development For Teachers Memphis, TN, USA: Poster presentation at the University of Memphis Annual Research Forum.

Roeser, R. (2016). "Processes of Teaching, Learning and Transfer in MindfulnessBased Interventions (MBIs) for Teachers: A Contemplative Educational Perspective," in The Handbook of Mindfulness in Education: Integrating Theory and Research into Practice. doi:10.1007/978-1-4939-3506-2_10

Ross, A., Bevans, M., Friedmann, E., Williams, L., and Thomas, S. (2014). "I Am a Nice Person when I Do Yoga!!!" A Qualitative Analysis of How Yoga Affects Relationships. J. Holist. Nurs. 32 (2), 67-77. doi:10.1177/0898010113508466

Rubin, H. J., and Rubin, I. S. (2007). Qualitative Interviewing: The Art of Hearing Data. Organizational Res. Methods 10 (1), 184-187.2nd ed.

Salmon, P., Lush, E., Jablonski, M., and Sephton, S. E. (2009). Yoga and Mindfulness: Clinical Aspects of an Ancient Mind/Body Practice. Cognitive Behav. Pract. 16 (1). doi:10.1016/j.cbpra.2008.07.002

Schneider, C. s., and Wagemann, C. c. (2015). Standards of Good Practice in Qualitative Comparative Analysis (QCA) and Fuzzy-Sets. Comp. Sociol. 14 (1), 397-418.

Scopus. (2015). Jones, Mary. Retrieved Accessed April 24, 2015, from Available at: http://www.scopus.com/

Seligman, M. (2003). Positive Psychology: Fundamental Assumptions. Psychologist $16,126-127$.

Skulmowski, A., and Rey, G. D. (2018). Embodied Learning: Introducing a Taxonomy Based on Bodily Engagement and Task Integration. Cogn. Res. Princ Implic 3, 6. doi:10.1186/s41235-018-0092-9

Subedi, S. (). Exploring Different Types of Hatha Yoga for Patients with Cancer. Clin. J. Oncol. Nurs. 18 (5), 586-590. doi:10.1188/14.CJON.586-590

Tyberg, J. (1940). Sanskrit Keys to the Wisdom Religion California: Theosophical University Press.

Usher, E. L., and Pajares, F. (2008). Sources of Self-Efficacy in School: Critical Review of the Literature and Future Directions. Rev. Educ. Res. 78 (4), 751-796. doi:10.3102/0034654308321456

Vygotsky, L. S. (1978). Mind in Society: The Development of Higher Psychological Processes. Cambridge, MA: Harvard University Press.

Waechter, R., Stahl, G., Rabie, S., Colak, B., Johnson-Rais, D., Landon, B., et al. (2021). RE: Mitigating Medical Student Stress and Anxiety: Should Schools Mandate Participation in Wellness Intervention Programs. Med. Teach., 1-2. doi:10.1080/0142159X.2021.1993580

Conflict of Interest: The author declare that the research was conducted in the absence of any commercial or financial relationships that could be construed as a potential conflict of interest.

Publisher's Note: All claims expressed in this article are solely those of the authors and do not necessarily represent those of their affiliated organizations, or those of the publisher, the editors and the reviewers. Any product that may be evaluated in this article, or claim that may be made by its manufacturer, is not guaranteed or endorsed by the publisher.

Copyright $\odot 2021$ Reeves and White. This is an open-access article distributed under the terms of the Creative Commons Attribution License (CC BY). The use, distribution or reproduction in other forums is permitted, provided the original author(s) and the copyright owner(s) are credited and that the original publication in this journal is cited, in accordance with accepted academic practice. No use, distribution or reproduction is permitted which does not comply with these terms. 